\title{
Desarrollo económico y actividad pesquera en el sur de Cataluña
}

\author{
Rafael Böcker Zavaro \\ Universitat Rovira i Virgili \\ rafael.zavaro@urv.cat
}

Resumen: En este artículo se exponen los resultados de una investigación que trata de determinar las características del desarrollo pesquero en la provincia de Tarragona, pero no sólo desde el punto de vista económico, sino también desde el social, el territorial y el de las politicas públicas instrumentadas para este sector. Nos interrogamos acerca del papel desempeñado por los diferentes actores sociales, económicos e institucionales y sobre el significado de la gestión pesquera sostenible y responsable.

Palabras clave: desarrollo, pesca, Cataluña

\begin{abstract}
This article sets out the results of research that aims to determine the characteristics of fishing development in the province of Tarragona not only from the social, territorial, and economic point of view, but also from the perspective of the public policies implemented in this sector. It discusses the role played by the various social, economic and institutional agents, and the importance of the sustainable and responsible management of fishing.
\end{abstract}

Keywords: development, fishing, Catalonia 


\section{Introducción}

En las últimas décadas, la provincia de Tarragona ha experimentado cambios y transformaciones sociales y económicas de gran importancia. La industria, con una notable diversificación, está principalmente situada en la costa y en las ciudades, y es uno de sus principales motores económicos. No solo el área de Tarragona capital se ha convertido en el centro petroquímico más importante del sur de Europa, sino que, además, su puerto ha pasado a ser el segundo de España — tras el de Bilbao- en tráfico de mercancías. De este importante desarrollo no están exentas otras actividades económicas, como es el caso de la pujante actividad pesquera de la región, localizada en siete puertos pesqueros: Torredembarra, Tarragona, Cambrils, L'Ametlla de Mar, L'Ampolla, Sant Carles de la Ràpita y Les Cases d'Alcanar. Por ejemplo, los de Tarragona y Sant Carles de la Ràpita se han consolidado como los más importantes de Cataluña. Este hecho cobra mayor relevancia económica si tenemos en cuenta dos aspectos: por el lado de la oferta, se trata de un nutrido conjunto de puertos marítimos emplazados a lo largo de $80 \mathrm{~km}$ de costa; por el lado de la demanda, el consumo de pescado fresco por parte de la población catalana no queda cubierto por su propia pesca, que sólo satisface la demanda en un $20 \%$. Por este motivo, el abastecimiento de la población de Barcelona y de otros núcleos urbanos de Cataluña depende mayoritariamente de las remesas cotidianas de pescado de las regiones gallega y cantábrica. Esta situación se explica porque se trata de un recurso valioso pero escaso en el Mediterráneo, con un gran mercado consumidor cuya demanda supera ampliamente la oferta.

Ahora bien, surgen numerosas e importantes preguntas en materia de desarrollo pesquero en la provincia de Tarragona que reclaman respuesta ¿Cuáles son los modelos pesqueros actuales? ¿Qué significan en términos de pesca real? ¿Cuál es el potencial de la actividad pesquera en estos puertos? ¿Cuáles son los mayores desafíos para el sector? ¿Qué vinculaciones se establecen entre las cofradías y las distintas administraciones? ¿Cómo intervienen las distintas administraciones en la actividad pesquera?

\section{El desarrollo pesquero como problemática social}

La revisión bibliográfica muestra que las pesquerías marítimas del Mediterráneo son de dos tipos, tienen organizaciones socioeconómicas completamente distintas y están encabezadas por dos grupos sociales diferentes: a) las pesquerías comunitarias o pesca artesanal, que representan la tradición original de la pesca marina en el Mediterráneo, y $b$ ) las pesquerías semiindustriales, que han apareci- 
do en tiempos relativamente recientes, aunque existen algunos precedentes históricos importantes. De la distinción y definición de cada una de ellas dependerá la posibilidad de describir su situación y de explicar sus estrategias colectivas en la provincia de Tarragona. El problema social de fondo es que las comunidades pesqueras del Mediterráneo se ven frecuentemente desposeídas de su espacio y sus recursos, no sólo en beneficio de los profesionales de la industria pesquera, sino también por intereses industriales, turísticos o urbanos. Por ello, el Estado no sólo debe ejercer sobre el mar formas de control vinculadas con el comercio marítimo, las aduanas, la seguridad en el mar, los límites marítimos, etc., sino también aquellas relacionadas con la vigilancia de la pesca, los puertos, la planificación urbana, el medio ambiente y la condición jurídica de los marineros. Por su parte, las cofradías de pescadores españolas son interlocutores del Estado y los gobiernos autonómicos y están organizadas en federaciones, lo que les da cierto peso a escala regional y nacional. Y si bien se trata de corporaciones profesionales que representan a los pescadores en cuanto grupo - propietarios de los barcos, patrones y marineros-, son los propietarios quienes dominan casi completamente la institución, hecho que ha contribuido probablemente a eliminar sus raíces comunitarias. Además, las cofradías cumplen funciones reguladoras en su territorio, centrándose principalmente en la disciplina del mercado y en las controversias entre los propietarios de los barcos y los marineros. Autores españoles como Alegret (1990, 1998), desde la antropología, y Franquesa $(1997,2004)$, desde la economía, se han ocupado de este asunto.

El desarrollo pesquero se analiza también a partir del concepto de territorio. El territorio es resultado de un proceso - Maillat (1999) habla de «territorio construido»- surgido de las estrategias de los actores y de fenómenos de aprendizaje colectivo. Por ello, partimos del supuesto de que el territorio deja de ser un mero soporte de los recursos y de las actividades económicas, ya que las empresas y los demás agentes sociales interactúan entre sí organizándose para desarrollar la economía y la sociedad. Ahora bien, en temas marítimos, a esta idea de territorio se agrega la noción de territorio marítimo. Así, por ejemplo, desde la perspectiva de la ecología humana y el marxismo, algunos antropólogos españoles, como García, Pascual Fernández y Sánchez, han planteado que las estrategias de los pescadores no sólo se sustentan en las opciones estrictamente tecnológicas o productivas, sino también en la protección de su territorio mediante la definición de modelos de acceso a los recursos y técnicas de pesca permitidas. No obstante, entre los factores que determinan el territorio de una comunidad pesquera no sólo están los relativos a la capacidad de las embarcaciones y las técnicas empleadas, las características de la costa y la diversidad de los lugares y recursos pes- 
queros, sino que el territorio puede definirse también basándose en los mercados y hábitos alimenticios. También puede definirse a partir de elementos psicosociológicos, como la memoria, religión, tabúes y creencias, en la medida en que pueden limitar o demarcar también territorios existentes, introduciendo la idea de uso conjunto de la comunidad. Por su parte, la industria pesquera se construye sobre la negación de los territorios de las comunidades, ya que las pesquerías semiindustriales no reconocen ningún límite espacial al ejercicio de sus actividades. Mientras los territorios de las comunidades se han construido a partir de una historia concreta de las distintas comunidades, la pesca semiindustrial se basa en el principio de la libertad individual de acceso a los recursos pesqueros. En efecto, el derecho de las unidades semiindustriales - flotas cerqueras y arrastreras - a penetrar y faenar en todas las zonas marinas de los Estados ribereños ha sido reconocido en todos los países del Mediterráneo occidental.

El territorio donde se localizan las actividades pesqueras ofrece una serie de infraestructuras portuarias que, en su conjunto, se denominan espacio portuario o, específicamente, puerto pesquero. Por ello, el desarrollo pesquero ha de analizarse a partir de las infraestructuras portuarias donde se desempeña, en tanto que los puertos son espacios de vinculación entre el territorio de la región y los territorios marítimos. Ya en los años sesenta del pasado siglo, Hernández Yzal (1968), desde la perspectiva de la economía marítima, planteó que los puertos pesqueros pueden dividirse en dos grandes grupos. El primero sería el de los puertos pesqueros en su pura acepción marinera: los puertos de la provincia pertenecen a este tipo de puerto. Se trata de dársenas o partes de puertos en las cuales se provee el atraque de las embarcaciones y los buques de pesca. Las instalaciones portuarias suelen ser simples y disponen de varadero como instalación para coadyuvar a reparaciones sustanciales de obra viva de los buques de pesca. Además, cuando se descarga el pescado es directamente transportado, por medios ordinarios, a los centros de contratación (lonjas, mercado) para su venta y consumo. Por ello, suelen existir fábricas de hielo para la conservación del pescado a bordo y en los depósitos de la lonja, de modo que resulte asegurada su conservación hasta la primera venta. El segundo grupo sería el de los puertos de centros industriales pesqueros: disponen de una más compleja estructuración de servicios, tales como cámaras frigoríficas, plantas accesorias de preparación de filetes y envasado, así como almacenes para contener el producto del ciclo industrial una vez terminado. Ello apareja, además, la necesidad de disponer de muelles comerciales para el embarque del pescado envasado y demás instalaciones habituales de estos muelles. 
Otra esfera desde la que puede enfocarse el desarrollo pesquero es la de la organización jurídica e institucional del sector y sus políticas públicas. En la actualidad, la perspectiva marxista ha derivado en planteamientos más cercanos a la economía política, como es el caso de Galván (1993), Cabrera (2000) y Florido (2002). Estos autores han intentado enlazar las poblaciones locales y los recursos que utilizan con marcos sociales e históricos más amplios, analizando la articulación entre agentes y relaciones locales de poder y marcos políticos y administrativos más amplios. En este sentido, puede destacarse que las políticas estatales, científicas y centralizadas, estimularon y crearon pesquerías industriales después de la II Guerra Mundial por medio de subvenciones y transferencia tecnológica - en España este proceso comenzó a partir de la década de 1970, al estimular las autoridades públicas la extensión de las tecnologías pesqueras y medios logísticos-. En términos socioeconómicos, la «industrialización pesquera» puede considerarse como un proceso de intervención en el que la administración pública (especialmente la estatal) absorbió las distintas funciones sociales que anteriormente desempeñaban las comunidades en la organización del sector. Progresivamente, han sido aplicados por los Estados del Mediterráneo su derecho de custodia y el principio de la libertad de pesca, con lo que se ha privado a las comunidades de sus derechos tradicionales en beneficio de la pesca semiindustrial, ya que se trata de unidades poderosas que monopolizan el acceso a la parte principal de los recursos. Y, si bien actualmente existe una importante flota semiindustrial en el Mediterráneo, el sector padece una crisis general: crisis de recursos pesqueros, crisis del mercado de muchos productos pesqueros debido a la competencia vinculada con la globalización, crisis de las empresas pesqueras que se enfrentan con deudas y costos de producción crecientes, crisis social, en definitiva, de las sociedades marítimas, que se ha traducido en una crisis demográfica con un empobrecimiento de las poblaciones de pescadores.

Resulta importante situar teóricamente los fundamentos de estas políticas, pues de ello se derivan las posibilidades para evaluar la capacidad de los gestores en el impulso de políticas de asignación territorial, así como la capacidad de las comunidades para participar decididamente en los procesos de cambio. Existen dos tipos de políticas de desarrollo local y regional claramente diferenciados, y cada uno está asociado a una específica política pesquera: 1) políticas de desarrollo exógeno: fundamento de las políticas estatales de «industrialización pesquera», y 2) políticas de desarrollo endógeno: vinculadas a aquellas políticas pesqueras más recientes de carácter «territorial, sostenible y responsable». Así, las políticas de desarrollo exógeno, que transcurren durante las décadas de los cincuenta y sesenta, incentivaban la atracción de capitales y empresas externas para impulsar el 
crecimiento económico de las regiones periféricas. Esta percepción del desarrollo se tradujo en las denominadas políticas nacionales de polos de desarrollo, que aplicaron la «Teoría del gran desarrollo y los rendimientos crecientes» de Hirschman (1970), Myrdall (1957) y Perroux (1955). Dichas políticas no dependen necesariamente, para atraer inversiones al territorio, de la acción de los mercados privados, pues emanan del Estado nacional y los efectos positivos de estas inversiones en el desarrollo del territorio se consideran, en cierta medida, garantizados, independientemente del tipo de relaciones que establece la aglomeración de empresas con el territorio, la estructura que adopta la aglomeración y su relación con el contexto institucional local.

En la década de los setenta comenzó a configurarse una estrategia de desarrollo alternativo basado en actores, recursos y capacidades locales y regionales, tal como queda plasmado posteriormente en las obras de Storper (1990), North (1993), Sforzi (1999) y Bacattini y Rullani (1996). Las políticas de desarrollo endógeno se sustentan en la idea de que las economías de las regiones y localidades pueden crecer utilizando el potencial de desarrollo existente en el territorio. El punto de partida del desarrollo endógeno es el conjunto de recursos (económicos, humanos, institucionales y culturales) que constituyen su potencial de desarrollo. La capacidad de liderar el propio proceso de desarrollo, unido a la movilización de su potencial, es lo que permite dar a esta forma de desarrollo el calificativo de endógeno. En este sentido, la organización de las sociedades marítimas en el Mediterráneo también plantea la cuestión del desarrollo endógeno y la descentralización de las medidas públicas. Recordemos que los gobiernos regionales tienen una función cada vez mayor en la inversión y asistencia a las empresas pesqueras - tal es el caso de los servicios de la Generalitat de Cataluña en el ámbito del Departamento de Agricultura, Ganadería y Pesca-, de modo que establecen políticas pesqueras reales en sus planes regionales.

Por otra parte, además de territoriales, se trata de políticas orientadas, real o retóricamente, a una pesca sostenible y responsable. Así, la historia del sector pesquero en España está plagada de conflictos en torno a la interacción entre artes y técnicas de pesca diferentes. De acuerdo con Alegret (1990, 1998), el argumento universal para oponerse al uso de ciertas artes o formas de pesca era el riesgo que suponían para la conservación de los recursos, lo que hoy llamaríamos su uso sostenible. El concepto «sostenible» busca, en general, hacer coherentes las exigencias ambientales con las del desarrollo económico, desde un punto de vista de largo plazo: así, en el informe Brundtland de 1989, se acuñó la definición más comúnmente utilizada del concepto de desarrollo sostenible, al entender que el modelo de crecimiento imperante es insostenible para el planeta y amenaza la 
disponibilidad por parte de las generaciones venideras de determinados recursos no renovables que, en el momento actual, son consumidos sin límite alguno. En la teoría económica, por ejemplo, los modelos bioeconómicos tratan de relacionar la reproducción de un recurso renovable con su explotación motivada por fines económicos. Es decir, estos modelos intentan explicar la naturaleza del equilibrio entre la industria pesquera y los principios de ordenación y conservación de las especies, buscando optimizar la explotación y definir políticas gubernamentales de manejo sustentable.

El concepto de responsabilidad, por su parte, constituye una vía de las empresas para la competitividad responsable socialmente. No obstante, la responsabilidad social de la empresa no deja de ser un concepto ambiguo, en la medida en que «significa algo distinto para cada cual. Para unos, se refiere a la idea de responsabilidad legal u obligación jurídica; para otros, significa una conducta socialmente aceptable en términos éticos; para otros aún, denota aquellas consecuencias de las que la empresa es causa directa. Muchos la entienden como filantropía. Otros la igualan a la conciencia social» (Votaw, 1972:25). No sólo esta idea ha sido desarrollada por la antropología y la sociología especializadas en temas pesqueros, sino también por la economía, como es el caso, por ejemplo, de Franquesa y Perez (1997). Estos autores entienden por pesca responsable aquella que ejerce la empresa individual bajo las limitaciones que se derivan de un sistema de gestión que le obliga a asumir las externalidades que la explotación pesquera genera al capturar el recurso.

\section{Diseño metodológico}

El método de investigación que hemos elegido es el estudio de caso, en la medida en que se refiere a la investigación de uno o pocos casos, en un grado de considerable profundidad y a lo largo del tiempo. Se trata de una metodología que nos permite producir, desde el punto de vista de la sociología, representaciones que describen y explican una realidad relevante para la provincia de Tarragona: el desarrollo de la pesca marítima. El análisis comparado resultante de sus siete puertos pesqueros es aún más significativo en la medida en que cuentan con volúmenes de facturación diversos, y cuyas pesquerías poseen distintos niveles de desarrollo e industrialización. Las técnicas empleadas para la recogida de la información han sido la entrevista semiestructurada, la observación no participante y el uso de fuentes secundarias estadísticas y documentales. Consideramos la entrevista en profundidad como uno de los instrumentos más apropiados para la recogida de información primaria, ya que permite detectar las interpretaciones 
que tienen los agentes económicos y los actores sociales e institucionales sobre el fenómeno de estudio, el sentido que dan a sus acciones y las expectativas que promueven. También creemos adecuada la utilización de la observación no participante, pues es una técnica que se basa en la recogida de información a través de la observación de acciones, hechos y sistemas con el objetivo de interpretarlos. En la investigación que nos ocupa, es idónea para registrar el proceso productivo y la organización del trabajo de los pescadores, tanto a bordo como en tierra. No obstante, para convertirla en un instrumento científico de obtención de información es necesario orientarla y enfocarla a un objetivo concreto, planificarla sistemáticamente en fases y someterla a controles de veracidad y objetividad. Para realizar el trabajo empírico se han llevado a cabo distintas actividades: 1) reconocimiento del entorno institucional de los puertos pesqueros analizados y de sus principales actores sociales y agentes económicos; 2) sensibilización; 3) trabajo de campo mediante entrevistas en profundidad y observación no participante, y 4) procesamiento de los resultados y análisis de la información. Para el reconocimiento del entorno institucional asociado a las pesquerías de la provincia de Tarragona se confeccionó un mapa relacional de las instituciones y entidades vinculadas al mismo.

\section{Análisis de la información}

En España, el sector pesquero se divide en dos grandes sistemas de pesca: la pesca de bajura y la pesca de altura. La pesca de altura la desarrollan grandes empresas pesqueras, potentes armadores que poseen embarcaciones con gran capacidad de capturas en todo el mundo. También existen empresas de este tipo de origen español que, como cualquier empresa naviera, se han «desenganchado» fiscalmente de España y para radicarse en países de bandera de conveniencia; otras, obligadas por convenios internacionales, deben hacer abanderamientos mixtos. Las semiindustriales, por su parte, son embarcaciones de pesca de bajura de captura diaria, es decir, realizan salidas a la mar de no más de diez horas, aunque utilizan artes de pesca mecanizadas y automatizadas. En algunas zonas de España, la pesca de bajura presenta un estadio intermedio: barcos de un porte más importante que hacen campañas de más de un día, incluso de una semana, como en Andalucía, en Galicia, en el País Vasco, etc. Son flotas algo más itinerantes y alcanzan un volumen económico más importante. Y luego está la flota auténticamente de bajura, que hasta cierto punto podría llamarse artesanal, y que en España representa un porcentaje realmente pequeño. 
En Cataluña, excepto los seis barcos atuneros con base en L'Ametlla de Mar, la flota de pesca pertenece al tipo de bajura y es de un estilo muy arraigado a la porción de costa en donde trabaja. Es decir, que alcanza un peso muy relativo desde el punto de vista económico, pero en cambio está vinculada socialmente a cada lugar donde arraiga. Esto se debe a que existen numerosas empresas pesqueras pequeñas, esto es, armadores familiares.

En la provincia de Tarragona, las flotas de la ciudad de Tarragona y de Sant Carles de la Ràpita son de las más grandes, también en cuanto a volumen de capturas y puestos de trabajo. Les siguen, en primer lugar, la de L'Ametlla de Mar, luego la de Cambrils y finalmente las más pequeñas de Les Cases d'Alcanar, L’Ampolla y Torredembarra. Así, las primeras concentran las embarcaciones más grandes y semiindustriales (de arrastre y cerco), mientras que las últimas practican las artes menores (palangre y trasmallo). Y este desigual desarrollo pesquero afecta a otras actividades locales, como el turismo. Por ejemplo, si bien la actividad pesquera de Torredembarra cuenta con una dársena en el puerto deportivo inaugurado en 1994, no pudo desarrollarse de igual modo que los otros casos en estudio ya que hasta entonces la flota pesquera fondeaba en la misma playa. Mientras, en Cambrils el turismo se desarrolló en torno a los establecimientos de restauración de productos del mar del mismo puerto, lo que a su vez incidió en la necesidad de aumentar las capturas por parte de la flota de pesca local; en Torredembarra, el turismo no está asociado a la pesca y su gastronomía, sino al turismo de sol y playa. Y como esto no incentiva el aumento de las capturas, Torredembarra no se ha afianzado como una marca asociada a la pesca y a la gastronomía marinera, como sí sucede en los casos de Cambrils, del barrio del Serrallo de Tarragona, de Les Cases d'Alcanar o de Sant Carles de la Ràpita.

\section{Cuadro 1. Capturas, armadores y trabajadores en los puertos pesqueros} de la provincia de Tarragona (2009).

\begin{tabular}{|l|c|c|c|c|}
\hline & Capturas $(\mathrm{kg})$ & Armadores & Marineros & Mariscadores \\
\hline Torredembarra & $96.275,25$ & 12 & 9 & 0 \\
\hline Tarragona & $3.000 .262,15$ & 90 & 268 & 0 \\
\hline Cambrils & $2.053 .647,76$ & 37 & 150 & 0 \\
\hline L'Ametlla de Mar & $2.408 .795,22$ & 62 & 304 & 0 \\
\hline Sant Carles de la Ràpita & $3.070 .028,19$ & 86 & 220 & 29 \\
\hline Les Cases d'Alcanar & $257.294,65$ & 23 & 11 & 0 \\
\hline L'Ampolla & $233.816,55$ & 18 & 38 & 4 \\
\hline
\end{tabular}

Fuente: Elaboración propia, a partir de datos del Departamento de Agricultura, Alimentación y Acción Rural de la Generalitat de Cataluña. 
En general, la pesca de bajura que se practica en Cataluña se ha caracterizado por atender la demanda de pescaderías detallistas o de restauración de la zona, sobre todo en las cofradías en las que la lonja se ha mantenido con una cierta tradición, y los excedentes se subastan a compradores de otras partes de España. En los últimos tiempos, no obstante, esta tradición está cambiando, a remolque de la aparición de zonas de gran consumo - como Barcelona y su área metropolitana - cuya demanda no pueden satisfacer las flotas de la Barceloneta (Barcelona), Vilanova i la Geltrú y el ámbito cercano. De este modo, se compra pescado en el Mercado Mayorista de Barcelona (Mercabarna) procedente de lugares tan disímiles como Francia, Sudáfrica, el Cantábrico y, también, de los excedentes de la pesca de bajura catalana. Esta tendencia de comenzar a suministrar a través de grandes mercados como Mercabarna se ha ido extendiendo, sobre todo en la restauración. Es decir, el restaurador ya no acude a la lonja del pueblo a comprar para ofrecer una cocina personal, sino que espera que le llegue el repartidor de turno, porque el restaurador se ha convertido en un cocinero que no se mueve de los fogones. Como consecuencia, este repartidor, que sí le vende un pescado de calidad suficiente, ya no tiene en cuenta la procedencia, con lo que no se vende el pescado típico sino el que debe estar en la carta. De este modo, la carta se mantiene durante todo el año sin que se dependa de las capturas locales cambiantes de cada temporada. De todas formas, este fenómeno no es exclusivo del sector pesquero; por ejemplo, lo mismo pasa con las frutas y verduras: antes se accedía sólo a las de temporada, pero ahora tenemos al alcance a todas y durante todo el año.

En el proceso de producción pesquera intervienen distintos agentes económicos y comerciales (armadores, empresas pesqueras, propietarios de pescaderías, etc.) y actores sociales e institucionales (administración, cofradía, tripulación, trabajadores de tierra, etc.). Como ya se mencionó, la captura la realizan directamente los armadores, quienes a su vez son miembros de la cofradía. La empresa pesquera es la que toma las decisiones de pesca y captura, y luego la descarga en el muelle, donde empieza la función de la cofradía. El sector se organiza en cofradías de pescadores que tienen un carácter tutelar y ordenador de la actividad del sector. Disponen de autonomía propia, son corporaciones de derecho público y se agrupan en federaciones. Son, principalmente, una organización para la venta de pescado desde la lonja, para ofrecer servicios al pescador y para la coordinación entre los diferentes intereses.

De este modo, sin intervenir en la actividad pesquera en alta mar, las cofradías actúan hasta pie de muelle efectuando trámites diversos vinculados a servicios previos de la actividad, como es también el caso del suministro de hielo. Esto se debe a que las cofradías han sido absorbidas actualmente por la pesca semiindus- 
trial, por lo que prácticamente no desempeñan ninguna función en la autorregulación del esfuerzo de pesca, hecho que está vinculado en gran medida, por ejemplo, con los recientes conflictos por la veda anual de dos meses entre la cofradía de Sant Carles de la Ràpita y la Federación Territorial de Cofradías de Pescadores de Tarragona. No obstante, las cofradías disfrutan de poderes corporativos que les permiten controlar los mercados y que, mediante el establecimiento de redes de influencia, les proporcionan medios materiales y posibilidades de influir en las decisiones políticas. Recordemos, por poner un caso, la amplia participación de las cofradías españolas en la decisión de crear una zona de protección de los recursos en el Mediterráneo para su sostenibilidad.

Así, la cofradía, en tanto titular de la lonja y, en general, instrumento de comercialización mediante subasta pública, da sentido a una dársena pesquera. Es la encargada de atraer clientes que vengan a comprar, es decir, facilita la formación de un mercado para que el pescador le venda al pescadero: a la subasta pública asisten compradores de otras zonas, quienes efectúan compras para otros clientes que no asisten físicamente, como es el caso de algunos compradores de Vilanova i la Geltrú o Barcelona en las subastas de Torredembarra y Tarragona. Una vez que se ha producido la transacción, la cofradía efectúa el cobro y los trámites pertinentes. Existen en la provincia de Tarragona tres excepciones al sistema de subasta pública de las capturas en las cofradías. La de Cambrils es la única cofradía que compra toda la captura diaria, y posteriormente la vende a las pescaderías de su propiedad, y el excedente a otros compradores. Por su parte, la de Tarragona subasta las capturas de la flota de arrastre, mientras que el pescado azul es comprado en su totalidad por la firma Pescafresca, del grupo Pescanova, a raíz de un convenio pactado en los últimos años. Por último, en L'Ametlla de Mar comercializan los atunes y las doradas a pedido, después de mantenerlos en gavias frente a la costa.

En todos los casos del sur de Cataluña se vende o se subasta el pescado fresco, es decir, no existe ningún proceso artesanal o industrial posterior de fileteado, envasado o enlatado. No obstante, a diferencia del sistema de subasta pública, en los tres casos mencionados anteriormente existe cierto valor agregado: el pescado azul de Tarragona se envasa en cajas de porexpán sin agujeros, con agua, hielo y un poco de sal, para que pueda ser transportado en mejores condiciones. En L'Ametlla, los atunes se comercializan de acuerdo con los pedidos recibidos, congelándolos y enviándolos por avión a destinos como Japón, Francia o Italia. También existe una empresa que se dedica a la especie de la dorada: las alimentan desde que nacen en una gavia emplazada frente a la costa, y cuando alcanzan una medida mínima y reciben un pedido de compra, las sacan y las transportan a la 
central de Les Cases d'Alcanar para su comercialización. De este modo, la cofradía obtiene un porcentaje de los beneficios de la empresa. En Cambrils, y a diferencia de otros puertos que usan cajas de plástico para ocho o diez kilos, utilizan cajas de porexpán de un máximo de cuatro o cinco kilos para que el pescado se conserve más y mejor, y de esta forma puedan venderlo a un precio mayor.

Como ya hemos referido, Cambrils funciona de forma diferente del resto de los puertos pesqueros de Cataluña, en la medida en que su cofradía es la que compra y luego vende directamente la pesca, esto es, no realiza una subasta pública. Hace ya nueve años que el pescado que sacan las barcas de Cambrils se pesa, se etiqueta y se distribuye directamente. Por ello, los precios de los productos no se fijan en la lonja por medio de la subasta a la que asisten compradores, sino que es la propia cofradía, como única compradora, la que los fija a través de su director comercial. En la actualidad, la cofradía de Cambrils cuenta con la infraestructura de la lonja, aunque mantienen sólo las dos líneas de pesaje y etiquetado: datos de la barca que lo ha pescado y el peso y precio del producto. Luego, se coloca el pescado en unos palés para que los compradores puedan elegir y comprarlo fácilmente. Es importante mencionar que la cofradía posee seis pescaderías en la comarca del Baix Camp que venden al detalle, que en total sacan al mercado cerca del $20 \%$ de lo que se pesca en su puerto, además de otros productos que se obtienen en Mercabarna y en otras regiones. Para el pescado que sobra se comunican con compradores de otras partes de Cataluña, Portugal o Francia, y así pueden distribuirlo rápidamente y evitar intermediarios.

La sostenibilidad es un concepto que, si ya es ambiguo en las actividades económicas en general, en la pesca posee muchos otros matices. La sostenibilidad de la actividad pesquera reside en cuánto se puede pescar de una especie de forma indefinida sin poner en peligro su futuro sobre la base de su población, mortalidad y fertilidad. En este sentido, la pesca de arrastre es poco sostenible por definición, ya que consume mucho gasoil, tiene una rentabilidad relativa y se ve obligada a realizar numerosos descartes, en la medida en que realiza capturas no selectivas, para seleccionar ejemplares de una única especie. De ahí la importancia de ejercer controles para orzar a los arrastreros a una pesca más selectiva que permita evitar el descarte. En cambio, las embarcaciones de pequeña escala, que poseen otras artes de pesca, desarrollan una pesca más sostenible. Así, por ejemplo, la pesca de bajura en el Mediterráneo realiza capturas en zonas muy concretas y de muy diversas especies, con lo que no se recurre al descarte.

Las medidas de gestión pesquera deben tomarse buscando el máximo consenso entre la Administración, el sector pesquero, el mundo científico y otros sujetos que tengan intereses legítimos, mediante los órganos que se decidan, como por 
ejemplo el Consejo Asesor de Pesca. Este consejo, constituido en enero de 2007, es un órgano consultivo, asesor, de colaboración, de participación y de impulso formado por representantes del sector pesquero y marítimo y de la Administración catalana. Su objetivo es la ordenación del sector pesquero, la acuicultura, el marisqueo, la pesca de recreo, las actividades marítimas, la investigación oceanográfica y todas las materias competentes del Departamento de Agricultura y Ganadería (DAR).

Las estadísticas disponibles indican que existe una clara tendencia bajista en las capturas pesqueras debido a la sobreexplotación de los caladeros, y que las medidas de reducción del esfuerzo han de ir acompañadas de mejoras en la elección de las artes. Se apunta la solución de incrementar la selectividad de las artes de pesca para posibilitar una pesca más responsable. Por ejemplo, la potencia de los motores instalados actualmente en la flota de arrastre está sobredimensionada si tenemos cuenta el estado de conservación de los caladeros. Así, las medidas de reducción del esfuerzo pesquero deben ser específicas para cada modalidad que trabaja en Cataluña y, al mismo tiempo, y para evitar la competencia desleal, deben ser aplicables a las flotas vecinas que pescan en los caladeros de Cataluña. Las paralizaciones temporales y la reducción de la jornada diaria de trabajo de las flotas pesqueras son medidas que conviene impulsar.

Respecto a los costos de producción en la actividad pesquera, podemos señalar a grandes rasgos que el principal coste es el del gasoil. Así, por ejemplo, el pesquero de arrastre que acude a la pesca de la gamba no sólo se adentra muy lejos en el mar, sino que utiliza su arte de pesca a una profundidad muy grande, con mucho cable y con notable gasto de gasoil para la cantidad de biomasa que pesca. Pero como los peces que pescan las arrastreros son de un valor económico importante, logran compensar estos mayores gastos. En el caso contrario tenemos el caso de la flota de pesca de Cambrils, ya que está especializada en las capturas de galeras y calamar cerca de la costa y a menos profundidad, con lo que pescan más volumen y a su vez consumen menos gasoil. Por su parte, el barco palangrero sólo gasta combustible para acudir al caladero, ya que no debe arrastrar su arte de pesca como el arrastrero, pero sí padece un gasto muy grande en cebo o carnada de sardina. Más allá de las diferentes artes de pesca utilizadas, lo cierto es que los gastos en gasóleo son altos debido a los horarios de pesca, establecidos de menos de diez horas, ya que se consume más con estas continuas idas y venidas que si se pudiera salir a pescar, por ejemplo, tres días, y luego volver.

No obstante, la sostenibilidad no depende exclusivamente del desarrollo pesquero no sostenible, es decir, de la sobrepesca o de la utilización de artes de pesca destructivas del recurso, sino también de la contaminación del agua como 
resultado de los vertidos industriales y urbanos a los ríos y al mar, lo que afecta sin lugar a dudas al recurso pesquero. Esta situación es mucho más grave en la pesca de bajura desarrollada mayoritariamente en Cataluña, ya que estas embarcaciones efectúan sus capturas muy cerca de la costa, donde la contaminación del mar es aún mayor. Por ello, aun cuando se implementan vedas para una mayor recuperación del recurso pesquero, la contaminación del mar se presenta como la gran limitación a resolver, sea mediante mayores controles que eviten vertidos industriales, sea con una mayor puesta en funcionamiento de depuradoras de residuos urbanos.

Frente a estas problemáticas del sector se implementan políticas pesqueras a distintos niveles. Así, en la provincia de Tarragona la Generalitat actúa en el sector pesquero a través del Servicio Territorial de Tarragona de la Dirección General de Pesca del DAR. La Generalitat tiene competencia exclusiva en pesca, recogida de marisco y acuicultura en la zona costera catalana. Por ejemplo, puede legislar para delimitar un periodo de parada temporal con la que el sector tendrá derecho a una ayuda. También puede regular la ayuda en la adquisición de un motor, pero no las características de esta ayuda, que es competencia del Estado. También tiene competencias de inspección y de imponer sanciones.

El Estado se reserva toda la ordenación pesquera, sin perjuicio de las competencias de las comunidades autónomas en ordenación del sector pesquero. Dicha ordenación consiste en la regulación del sector económico o productivo, esto es, quiénes son los que pueden ejercer la pesca y bajo qué forma de organización. El Estado no legisla sobre marisquería, que es competencia de la Generalitat dentro de su zona. No obstante, a menudo se han producido conflictos de competencias entre el Estado y la Generalitat por la delimitación de la actividad normativa, puesto que el concepto de pesca marítima es genérico.

Por su parte, el Consejo de Ministros de la Unión Europea aprobó en 1999 el Reglamento (CE) por el cual se definieron las modalidades y condiciones de las intervenciones con finalidad estructural en el sector de la pesca, más conocido por las ayudas estructurales del programa IPOF para el periodo de vigencia 2000-2006. Durante el año 2007 las líneas de ayuda iban encaminadas a las siguientes prestaciones:

1) Ayudas para el fomento de medidas socioeconómicas a la actividad pesquera: línea de ayudas a los pescadores afectados por una paralización definitiva de buques pesqueros.

2) Ayuda para la paralización definitiva de la actividad de determinados buques pesqueros, para: a) el hundimiento sustitutivo del desguace. Sólo para las embarcaciones de madera y en aguas interiores; $b$ ) la asignación definitiva a la 
conservación del patrimonio histórico; c) la asignación definitiva a actividades de búsqueda, $y$ d) la asignación definitiva a actividades de formación pesquera de organismos públicos.

3) Ayudas a las acciones realizadas por los profesionales del sector pesquero. Se crea una línea de ayuda para fomentar la realización de proyectos de interés colectivo dirigida a: a) la gestión y control de la actividad y del esfuerzo pesquero; b) la mejora de las situaciones sanitarias, laborales y medioambientales, incluida su información; c) la modernización de los servicios que se dan al sector, y d) los sistemas de mejora de la calidad y el control de la innovación y del conocimiento de la producción, así como del comercio de los productos de la pesca y de la acuicultura.

4) Ayudas para las cofradías de pescadores y sus federaciones territoriales: el objeto de estas ayudas es sufragar parte de los gastos corrientes de las cofradías de pescadores y sus federaciones territoriales que presten servicios sociales, económicos, comerciales y administrativos.

5) Ayudas de mínimos al sector pesquero: se establece un régimen temporal de ayudas de mínimos al sector pesquero por haber contribuido al mantenimiento de su competitividad durante el ejercicio 2008.

El programa operativo esquemático para el periodo 2007-2013 prevé 9 líneas y diferentes actuaciones prioritarias:

1. Ayudas para la paralización definitiva de buques pesqueros.

2. Ayudas para la paralización temporal de la flota de arrastre y de cercamiento del litoral de Cataluña.

3. Inversiones a bordo de embarcaciones pesqueras y selectividad.

4. Compensaciones socioeconómicas por apoyar la gestión de la flota.

5. Acuicultura.

6. Acciones colectivas de los profesionales de la pesca.

7. Transformación y comercialización de los productos de la pesca y de la acuicultura.

8. Pesca costera artesanal.

9. Puertos de pesca, lugares de desembarco y fondeaderos.

\section{Conclusión}

Mediante esta investigación hemos querido comprender cuál es la situación del desarrollo pesquero en la provincia de Tarragona. El problema no es, en la actualidad, el de la modernización y el aumento de la capacidad de captura, que es ya superior a la capacidad de renovación de los recursos. Es, más bien, el de contro- 
lar y regular el esfuerzo de pesca a un nivel de compatibilidad con la base de recursos. Aunque hay que tener en cuenta, a su vez, que al sobreesfuerzo pesquero se suman una serie de factores, como por ejemplo la contaminación proveniente de los emisarios submarinos, la regeneración de playas, las obras y las ampliaciones portuarias, etc., que están menguando los caladeros pesqueros. Además, la actual crisis que sufre el sector no es tanto de rentabilidad económica — que se ve agravada por la subida de precio imparable del gasoil—, como debida al bajo precio que alcanzan en la lonja las capturas y de la casi nula diferenciación en el mercado detallista del pescado fresco de la costa con el foráneo. Por ello, resulta necesario evitar la comercialización de pescado fuera de la lonja, al considerar que esta práctica atenta contra la supervivencia y viabilidad económica de las cofradías de pescadores.

Se impone la necesidad de generar una gestión pesquera sostenible y responsable, orientada a un desarrollo endógeno integrador, en un proceso de construcción de consensos. En esta línea, el discurso de los encargados del sector es que desean cambiar el tipo de políticas de pesca y comienzan ya a hablar de políticas «territoriales» y pesca «sostenible y responsable», como ha sido el caso, por ejemplo, del establecimiento de una zona de protección pesquera en el Mediterráneo a fines de los años noventa. En este sentido apunta Martí Sans, Director General de Pesca y Acción Marítima, citado por Callau (2007:58), cuando afirma que «queremos una política pesquera que busque equilibrios, pero también aumentar todo aquello que nos dé garantías de futuro para el sector». Por ejemplo, Tarragona y la zona del Delta del Ebro es la zona donde se ha producido un incremento más importante de capturas, y es también donde se llevan a cabo vedas en el sector de arrastre y de cerco (pesca semiindustrial). Así como «el cerco realiza vedas en toda Cataluña, el arrastre sólo hace veda en Tarragona. Con los pescadores hemos hablado de esto y está claro que las vedas continuadas ayudan a estos resultados, ya que el pescado ha reposado dos meses».

En definitiva, es este tipo de desarrollo territorial, junto con políticas regionales acertadas, las que han permitido una recuperación de las capturas globales de pescado y productos del mar en Cataluña, que varía la tendencia de los últimos años: en 2006 se registró la cifra más alta desde 2002, después de un 2005 que representó el punto más bajo de los últimos diez años. El análisis territorial de los datos permite observar que las tendencias de incremento de capturas se mantienen en todas las demarcaciones territoriales. Por ello, institucionalmente se aconseja el mantenimiento de todas las medidas técnicas de gestión relativas a la limitación del esfuerzo pesquero. Modelo-medidas-gestión es una secuencia de la administración de gobierno en la que el último eslabón es tan relevante 
como los dos primeros, y el resultado no es igual si la eficiencia de la gestión es buena, poca o mediocre.

\section{Bibliografía}

Alegret, J. L. (1990)+ «Del corporativismo dirigista al pluralismo democrático: las cofradías de pescadores en Catalunya». Eres. Serie de Antropología, Tenerife, Museo Etnográfico, 2 (1): 161-172.

Alegret, J. L. (1998). «Property Rigths, Regulatory Mesures and Strategic Responses among the Fishermen of Catalonia», en Property Rigths, Regulatory Systems in Fisheries. Oxford: Blackwell Science, Fishing New Books.

Becattini, G. y Rullani, E. (1996). «Sistemas productivos locales». Información Comercial Española. Revista de Economía, 754: 11-24.

Bellandi, M. (2006). «El distrito industrial y la economía industrial. Algunas reflexiones sobre su relación». Economía industrial, 359: 43-57.

Böcker, R. (2005). Desarrollo, planificación estratégica y corporativismo local. El caso de Mar del Plata (Argentina). Reus: Manuscrito tesis doctoral, Universitat Rovira i Virgili.

Böcker, R. (2007). «Gestión pública local. El caso del Plan Estratégico de Mar del Plata (Argentina)». Revista de Gestión Pública y Privada, 12: 31-52.

Böcker, R. (2009). «Desarrollo pesquero. El caso de los puertos del Camp de Tarragona». Revista de Estudios Maritimos y Sociales, 2: 105-114.

Brunet, I. y Böcker, R. (2007). Desarrollo, industria y empresa. Madrid: Tecnos. Cabrera, G. (2000). Transformaciones socioeconómicas, organización del trabajo e ideologías de género: la población pesquera de La Graciosa desde una perspectiva de economía política. La Laguna: Universidad de La Laguna.

Callau, F. (2007)+ «Catalunya registra una recuperación del volumen de capturas de pesca». Europa Azul, 98: 58-59.

Coller, X. (2000). Estudio de casos. Madrid: Centro de Investigaciones Sociológicas.

DAR (2007). Estadísticas del sector pesquero catalán. Barcelona: Departamento de Agricultura, Alimentación y Acción Rural (DAR).

FÉrAL, F. (2004). Sociedades, legislación pesquera e instituciones maritimas en el mediterráneo occidental. Roma: FAO.

Florido, D. (2002). Estado, asociacionismo y poder local en la conformación de la politica pesquera. Análisis comparativo de los casos de Barbate y Conil de la Frontera (Cádiz). Departamento de Antropología Social. Sevilla: Universidad de Sevilla. 
Franquesa, R. (1997). Modelos bioeconómicos y politicas de regulación pesquera. Una lección introductoria. Madrid: Ed. Consejería de Medio Ambiente, Agricultura y Agua.

Franquesa, R. (2004). Fishermen Guilds in Spain (Cofradias): Economic Role and Structural Changes. Londres: IIFET.

Franquesa, R+y Pérez, R. (1997)+ «The Quotient of Convenienceः Estimation of The Cost Relative to Responsible Fishing, Towards Sustainable Fisheries». Issue Papers. OECD:229-245.

Franquesa, R.; Malouli, I. M., y Alarcón, J. A. (1999). Estudio de evaluación de viabilidad del establecimiento de una base de datos de indicadores socioeconómicos para la pesca en el Mediterráneo. FAO-COPEMED.

Galván, A. (1993). «Entre la tierra del común y la mar de todos: una cuestión de economía política y ecología humana», en Pascual Fernández, J. (coord.). Procesos de apropiación y gestión de recursos comunales. Santa Cruz de Tenerife: Asociación Canaria de Antropología, VI Congreso de Antropología.

GArcí A, A. (1990)+ «Del libre acceso a la propiedad comunalः el caso de la comunidad pesquera de Muxía». Eres. Serie de Antropología, 2: 99-114.

García, A. (1994). Estrategias económicas, innovación tecnológica y territorialidad en las comunidades pesqueras de Lira y Muxia. Santiago de Chile: Departamento de Antropología, Universidad de Santiago.

Hernández, S. (1968). Economía marítima. Barcelona: Cadí.

Hirschman, A. (1970). La estrategia del desarrollo económico. México: Fondo de Cultura Económica.

López-Aranguren, E. (1998). «El análisis de contenido», en El análisis de la realidad social. Métodos y técnicas de investigación. Madrid: Alianza Editorial.

Maillat, D. (1999). «Sistemas productivos regionales y entornos innovadores». En OCDE. Redes de empresas y desarrollo local: Competencia y cooperación en los sistemas productivos locales, pp. 75-90.

Martínez, M. (1999). «La definición de los problemas públicos y la legitimación de una normativa pesquera: "Asusto: nasa fanequera"», en Antropología de la pesca. Actas del VIII Congreso de Antropología. Santiago de Compostela: Asociación Galega de Antropología.

Myrdall, G. (1957). Economic theory and underdeveloped regions. Londres: Guckworth.

North, D. (1993). «Institutions and Credible Commitment». Journal of Institutional and Theoretical Economics, 149 (1):11-23. 
Pascual, J. (2003). «La actividad pesquera en Canarias en el contexto de la globalización», en Las expresiones locales de la globalización: México y España. México: Universidad Iberoamericana, Ciesas y Porrúa.

Perroux, F. (1955). «Note sur la notion de "Pôle de croissance"». Économie Appliquée, 8: 307-320.

PI-Sunyer, O. (1977). «Through Native Eyes: Tourists and Tourism in a Catalan Maritime Community», en Hosts and Guests. The Anthropology of Tourism. Philadelphia: University of Pennsylvania Press.

Pla Estratègic del Camp de Tarragona (2006). Quimica, turisme i sectors emergents. L'estructura productiva del Camp. Tarragona: Càpsula de Futur.

SÁnchez, J. O. (1992). Ecología y estrategias sociales de los pescadores de Cudillero. Madrid: Siglo XXI.

Santana, A. (1990). Desarrollo turístico e impactos medioambientales sobre dos poblaciones pesqueras insulares (Arguineguín y Playa de Mogán, Gran Canaria). La Laguna: Departamento de Prehistoria, Antropología e Historia Antigua, Universidad de La Laguna.

Seijo, J. C.; Defeo, O., y Salas, S. (1997). Bioeconomía pesquera. Teoría, modelación y manejo. Roma: FAO, Documento Técnico de Pesca 368.

Sforzi, F. (1999). «Sistemas locales de empresa y transformación industrial en Italia», en Manual de desarrollo local. Gijón: Ediciones Trea.

Storper, M. (1990). «Industrialization and the regional question in the Third World: lessons of post-imperialism; prospects of post-Fordism». International Journal of Urban and Regional Research, 14 (3): 423-445.

Vallés, M. (2000). Técnicas cualitativas de investigación social. Reflexión metodológica y práctica profesional. Madrid: Síntesis.

Varela, M.; Surís, J; Garza, M. D., e Iglesias, C. (1998). Análisis de los mecanismos de regulación en pesquerías dirigido al estudio y valoración de los sistemas de licencias y cuotas. A Coruña: Instituto de Estudios Económicos de Galicia.

Votaw, D. (1972). «Genius Became Rare: A Comment on the Doctrine of Social Responsability Pt 1». California Management Review, 15 (2): 21-29. 